\title{
National Cancer Institute scientific production scientometric analysis
}

\section{Alí Ruiz-Coronel, ${ }^{1 *}$ José Luis Jiménez-Andrade ${ }^{2}$ and Humberto Carrillo-Calvet ${ }^{3}$}

${ }^{1}$ Instituto Nacional de Cancerología; ${ }^{2}$ Consejo Nacional de Ciencia y Tecnología, Center for Research and Innovation in Information and Communication Technologies; ${ }^{3}$ Universidad Nacional Autónoma de México, Faculty of Sciences, Laboratory of Non-linear Dynamics. Mexico City, Mexico

\begin{abstract}
Introduction: Scientometrics allows analyzing scientific publications productivity and impact through bibliometric and computational techniques. Objective: To propose a multidimensional methodology in order to obtain the scientometric profile of the National Cancer Institute (INCan), Mexico, and rank it with regard to other national health institutions. Method: Using the LabSOM software and the ViBlioSOM methodology based on artificial neural networks, the INCan scientific production indexed in the Web of Science from 2007 to 2017 was analyzed. The multidimensional scientometric profile of the Institute was obtained and compared with that of other national health institutions. Results: In terms of productivity, INCan ranks fourth among the 10 Mexican public health institutions indexed in the Web of Science; in the normalized impact ranking, it ranks sixth. Although out of 1323 articles 683 (51.62 \%) did not receive citations, 11 articles classified as excellent (0.83\%) obtained $24 \%$ of 11,932 citations and, consequently, INCan normalized impact rate showed a mean productivity higher than the world mean. Conclusion: Multidimensional analysis with the proposed neural network enables obtaining a more reliable and comprehensive absolute and relative institutional scientiometric profile than that derived from measuring isolated variables.
\end{abstract}

KEY WORDS: Research in public health systems. Outcome measure. Mexico.

\section{Análisis cienciométrico de la producción científica del Instituto Nacional de Cancerología}

\section{Resumen}

Introducción: La cienciometría permite analizar la productividad e impacto de las publicaciones científicas mediante técnicas bibliométricas y computacionales. Objetivo: Proponer una metodología multidimensional para obtener el perfil cienciométrico del Instituto Nacional de Cancerología (INCan), México, y compararlo respecto a otras instituciones nacionales de salud. Método: Con el programa LabSOM y la metodología ViBlioSOM, basada en redes neuronales artificiales, se analizó la producción científica del INCan indexada en la Web of Science entre 2007 y 2017. Se obtuvo el perfil cienciométrico multidimensional del Instituto y se comparó con el de otras instituciones nacionales de salud. Resultados: En productividad, el INCan ocupa el cuarto lugar de las 10 instituciones mexicanas de salud pública indexadas en la Web of Science.; en el ranking de impacto normalizado, el sexto lugar. Aun cuando de 1323 artículos, 683 (51.62 \%) no recibieron citas, 11 artículos de excelencia (0.83 \%) lograron 24 \% de 11932 citas y, consecuentemente, el impacto normalizado del INCan evidenció una productividad media por arriba de la media mundial. Conclusión: El análisis multidimensional con la red neuronal propuesta permite obtener un perfil cienciométrico institucional absoluto y relativo más fidedigno e integral que el derivado de conteos de variables aisladas.

PALABRAS CLAVE: Investigación en sistemas de salud pública. Medición de resultados. México.

Correspondence:

*Alí Ruiz-Coronel

E-mail: ali@sociales.unam.mx
Gac Med Mex. 2020;156:4-10

Contents available at PubMed www.gacetamedicademexico.com

0016-3813/@ 2019 Academia Nacional de Medicina de México, A.C.. Published by Permanyer. This is an open access article under the CC BY-NC-ND license (http://creativecommons.org/licenses/by-nc-nd/4.0/). 


\section{Introduction}

Article three of the National Cancer Institute (INCan - Instituto Nacional de Cancerología), Mexico, Organic Statute states that, for the fulfillment of its purpose, it shall:

Conduct clinical, epidemiological, experimental, technological development and basic studies and research in the biomedical and socio-medical areas in the specialty of neoplasms, for the understanding, prevention, diagnosis and treatment of diseases, and rehabilitation of those affected, as well as promote health measures. It shall also publish the results of the research and work that is carried out, as well as to disseminate technical and scientific information on the advances it achieves in matters of health. ${ }^{1}$

The research that is carried out at INCan is basic and clinical. Its integration is sought through translational research. In addition, clinicians are involved in research by evaluating medications and monitoring new protocols. From 2003 to 2013, an average of 186 research protocols were developed annually. ${ }^{2}$ How to know whether said research has the level of "excellence" dictated by the INCan mission?

One resource is scientometrics, which addresses the problem by analyzing scientific publications through bibliometric and computational techniques, incorporating algorithmic methods such as machine learning and data mining to generate indicators of productivity and impact of scientific production, ${ }^{3}$ such as cancer research. ${ }^{4-7}$ In Mexico, researchers are increasingly deciding what to investigate and where to publish based on scientometric criteria, given that their performance is assessed with that same methodology. Moreover, scientometric indicators are the main support for the allocation of resources for research. Especially when resources are limited and the costs of care are so high, as in the case of cancer, ${ }^{8,9}$ rigorous evaluation of scientific activity is essential. Therefore, we consider that scientometric analysis of INCan scientific production is, on one hand, an element for diagnosis of health research current situation in Mexico and, on the other, a contribution to future decision making. The methodology we propose can be transferred in order to obtain the scientometric profile of other national health institutions where research is part of their regular activities.

\section{Method}

With the LabSOM software, developed by the Laboratory of Nonlinear Dynamics of the Faculty of
Sciences of the National Autonomous University of Mexico, a scientiometric diagnosis of INCan scientific productivity was carried out through the analysis of the articles indexed in the Web of Science (WoS) during the 2007-2017 period.

The scientometric indicators obtained were the following:

- Total documents (Ndoc).

- Total cited documents (CD).

- Percentage of cited documents (CD \%).

- Total accumulated citations (TC).

- Average citations received by each article $(\mathrm{Cl})$.

- Hirsch index $(\mathrm{H})$.

- Impact relative to world (IRW).

- Category normalized citation impact (CNCl).

- Type of document and year.

- Total documents in national inter-institutional collaboration (NC).

- Total documents in international inter-institutional collaboration (IC).

- NC and IC percentages of Ndoc (IC \%)

- Percentage within $1 \%$ of the most cited articles worldwide (EXC \%).

- Percentage within $10 \%$ of the most cited articles worldwide (HP \%).

- Total hot papers (HP) or articles within $0.1 \%$ of the most cited in the previous two months.

- Total highly cited $(\mathrm{HC})$ papers or articles within $1 \%$ of the most cited in the year.

In addition, subject categories and scientific journals where INCan researchers have the highest number of publications and citations were identified.

To put these results in context, a comparison was made with the results obtained for other institutions. Initially, total scientific production of Mexico indexed in WoS during the 2007-2017 period was identified by institution, selecting through InCites those articles where at least one of the authors was a staff member of a Mexican institution. Subsequently, a second screening was made in order to focus on scientific production in the biomedical area. To this end, the production was screened based on eight research areas: Clinical Medicine, Biology \& Biochemistry, Immunology, Microbiology, Molecular Biology \& Genetics, Neuroscience \& Behavior, Pharmacology \& Toxicology and Psychiatry/Psychology, of the 22 areas defined by the European Scientific Institute classification system. The selection includes only scientific articles in journals (original articles and review articles), and excludes letters to the editor, revisions, abstracts and retracted articles. 
Table 1. Scientometric indicators of INCan WoS-indexed annual production for the 2007-2017 period

\begin{tabular}{|l|l|l|l|l|l|l|l|l|l|l|}
\hline Year & Ndoc & CD & CD $\%$ & TC & Cl & H & IRW & CNCI & IC & IC \% \\
\hline 2007 & 67 & 45 & 62.69 & 1212 & 18.09 & 17 & 0.897 & 0.82 & 13 & 19.4 \\
\hline 2008 & 78 & 55 & 69.23 & 1803 & 23.12 & 21 & 1.234 & 1.12 & 24 & 30.77 \\
\hline 2009 & 89 & 54 & 57.3 & 977 & 10.98 & 16 & 0.635 & 1.23 & 19 & 21.35 \\
\hline 2010 & 88 & 54 & 61.36 & 920 & 10.45 & 17 & 0.659 & 0.5 & 19 & 21.59 \\
\hline 2011 & 105 & 61 & 53.33 & 1144 & 10.9 & 19 & 0.785 & 0.87 & 21 & 20 \\
\hline 2012 & 125 & 73 & 57.6 & 1003 & 8.02 & 17 & 0.67 & 0.72 & 38 & 30.4 \\
\hline 2013 & 133 & 79 & 58.65 & 944 & 7.1 & 17 & 0.714 & 0.52 & 43 & 32.33 \\
\hline 2014 & 124 & 80 & 61.29 & 1320 & 10.65 & 14 & 1.35 & 1.25 & 52 & 41.94 \\
\hline 2015 & 142 & 73 & 50 & 2086 & 14.69 & 14 & 2.611 & 2.56 & 57 & 40.14 \\
\hline 2016 & 176 & 92 & 52.27 & 432 & 2.45 & 10 & 0.776 & 2.39 & 67 & 38.07 \\
\hline 2017 & 196 & 46 & 22.45 & 91 & 0.46 & 4 & 0.455 & 0.65 & 81 & 41.33 \\
\hline
\end{tabular}

Source: Own creation with WoS data. Ndoc = number of documents, $\mathrm{CD}=$ cited documents, $\mathrm{CD} \%=$ cited documents percentage, $\mathrm{TC}=$ total citations, $\mathrm{Cl}=\mathrm{citation}$ index, $\mathrm{H}=\mathrm{Hirsch}$ index $\mathrm{IRW}=$ impact relative to world, $\mathrm{CNCl}=$ category normalized citation impact, $\mathrm{IC}=$ international collaborations, $\mathrm{IC} \%=$ percentage of documents with international collaboration.

In this tool, the above-described indicators were chosen, health institutions were selected and two variables were added: number of researchers members of the National System of Researchers (SNI - Sistema Nacional de Investigadores) and institutional scientific production (SP), which was calculated by dividing the total number of documents by the number of researchers who are members of the SNI: Ndoc/SNI. ${ }^{10}$

Finally, a multi-parametric computational analysis was carried out using the ViBlioSOM methodology, which is based on the family of SOM (Self-organizing Maps) artificial neural network algorithms. This methodology, based on artificial intelligence, allowed to detect the scientometric profiles of the institutions and represent them through topographic clusters, according to their similarities. Briefly, the process carried out by ViBlioSOM consists of five steps: WoS data collection, data selection, cleaning and integration thereof, generation of the mathematical model and its processing through neural networks. The last step of the methodology is implemented in the LabSOM computational tool, which is freely distributed at: http://www. dynamics.unam.edu/DinamicaNoLineal3/labsom.htm.

\section{Results}

During the 2007-2017 period, 87 Mexican institutions published 146,933 articles indexed in WoS. Taking into account only the total number of articles, INCan ranked 33 with 1,405 documents. Out of these, 49,008 articles belonged to biomedical areas. In this ranking, INCan was $11^{\text {th }}$ with 1,323 articles.
Table 1 summarizes the information related to INCan. A steady, gradual growth can be observed in the number of documents, number of citations and number of international collaborations; except for two years, where there was a slight regression, 2010 and 2014, and two in which there was an atypical growth. This is because, in 2008, four articles together accumulated a total of 705 citations, which accounts for $39.1 \%$ of all citations for the 78 articles published that year. The other year is 2015 , when the most cited article throughout the period was published: "Nivolumab versus docetaxel in advanced non-squamous non-small-cell lung cancer", published in 2015 in the New England Journal of Medicine, a journal located in quartile 1 , as a result of a broad international contribution. This article concentrated 1,460 citations $(69.9 \%)$ of the 2,086 obtained by 142 articles published that year (Table 1).

Contrary to what it might be expected, the aforementioned article was a "highly cited paper", not a hot paper. No hot papers were found throughout the period. The 11 highly cited papers describe and discuss comparative results between treatments in cancer patients and are the result of international inter-institutional collaborations. During the period, 926 collaborations were recorded, involving 609 different institutions, as shown in Figure 1.

Naturally, oncology is the WoS subject category where INCan researchers published more (589) and more citations received (6004). Within this category, the most outstanding sub-subjects for the period were oncology, respiratory system, dentistry, surgery and obstetrics and gynecology. 


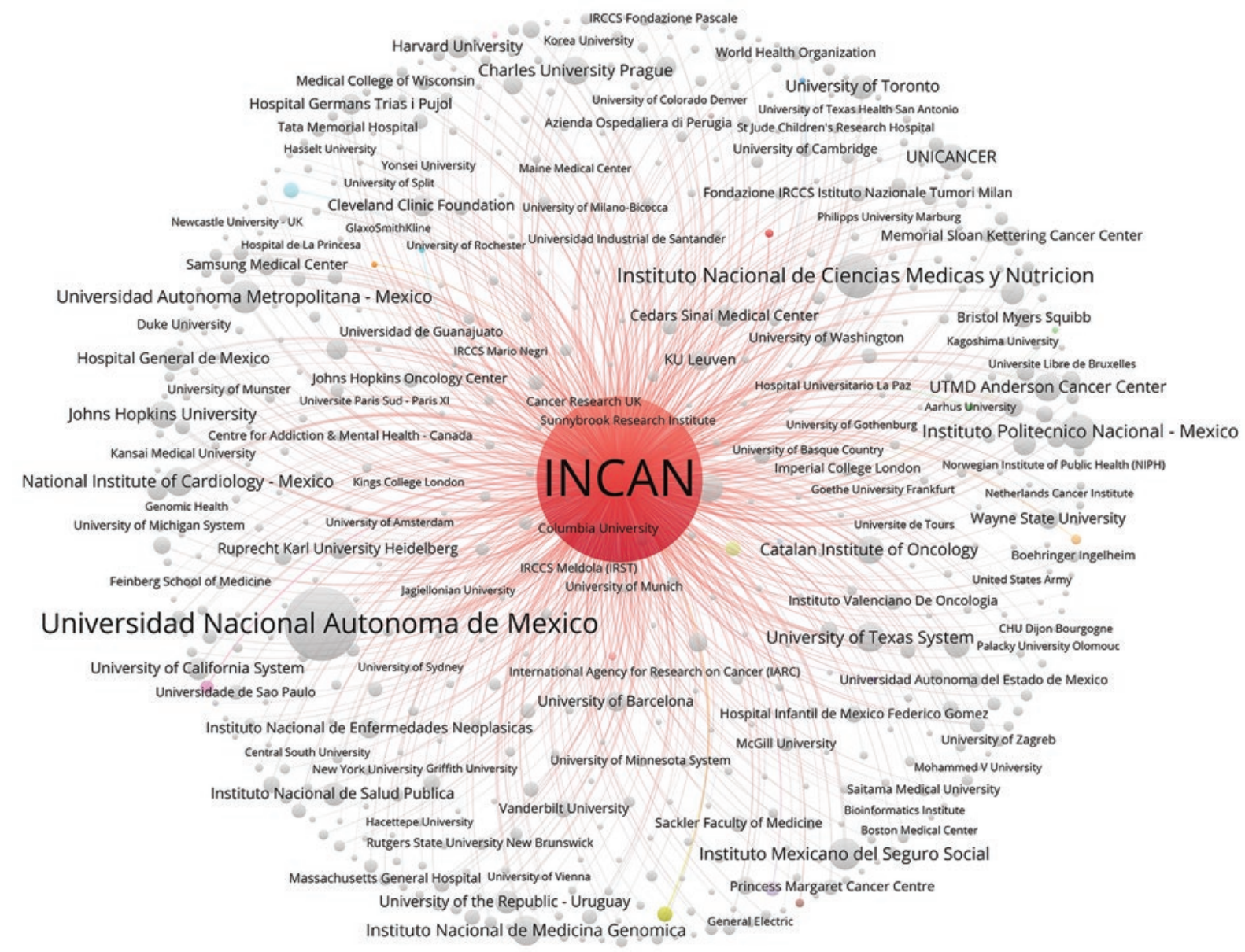

Figure 1. National Cancer Institute (INCan) collaboration links during the 2007-2017 period. Source: Own creation with WoS information using the free VOSviewer software tool (http://www.vosviewer.com).

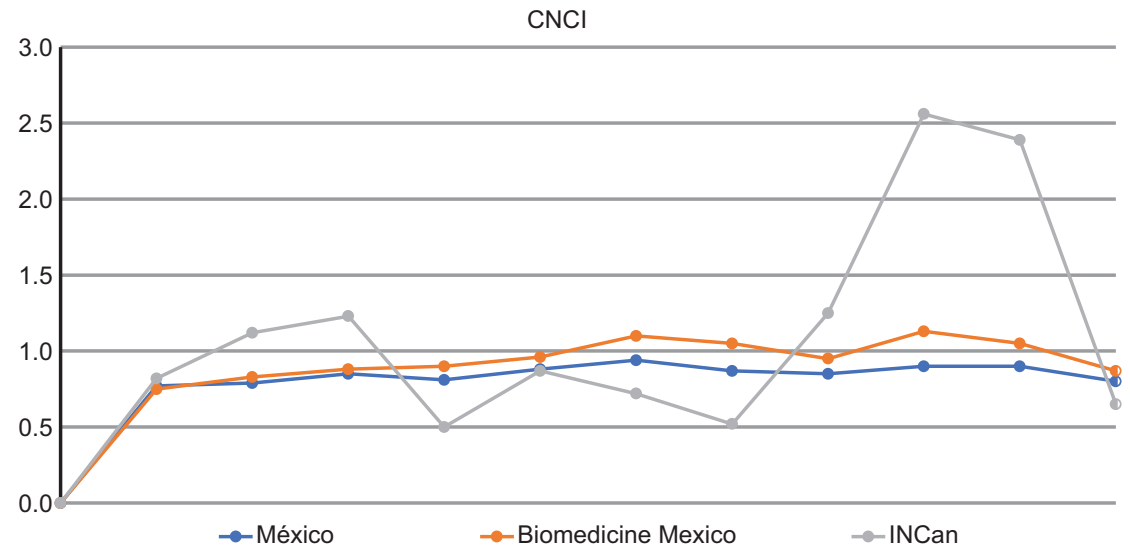

Figure 2. Subject category normalized citation impact. Source: Own creation with WoS data.

The category normalized citation impact $(\mathrm{CNCl})$ global ranking is an indicator that allows impact comparisons between different areas, since it normalizes citation styles. Through it, it is feasible to compare institutions with production in different areas, such as mathematics and biology. Figure 2 shows that biomedical production has consistently obtained more citations than the national mean. In addition, in 2012, 2013, 2015 and 2016, the $\mathrm{CNCl}$ indicator for biomedicine is higher than 1 , indicating 
Table 2. Scientometric indicators of health institutions with WoS-indexed production (2007-2017) in the biomedical area

\begin{tabular}{|c|c|c|c|c|c|c|c|c|c|c|c|c|}
\hline Rank & Name & Ndoc & CD \% & $\mathrm{Cl}$ & H & IRW & $\mathrm{CNCl}$ & IC $\%$ & EXC \% & HP \% & SNI & SP \\
\hline 3 & Mexican Institute of Social Security & 4121 & 62.12 & 8.35 & 68 & 0.5 & 0.76 & 26.13 & 0.73 & 5.44 & 324 & 12.7 \\
\hline 5 & $\begin{array}{l}\text { National Institute of Medical Sciences and } \\
\text { Nutrition "Salvador Zubirán" }\end{array}$ & 2764 & 59.59 & 11.01 & 68 & 0.66 & 1.14 & 34.52 & 1.59 & 8.21 & 189 & 14.6 \\
\hline 9 & National Institute of Public Health & 1601 & 64.77 & 22.05 & 73 & 1.33 & 2.77 & 60.46 & 4.68 & 14.55 & 185 & 8.6 \\
\hline 10 & National Institute of Cardiology & 1328 & 65.81 & 13.65 & 56 & 0.82 & 1.06 & 31.1 & 1.2 & 10.17 & 107 & 12.4 \\
\hline 11 & National Cancer Institute & 1323 & 52.15 & 9.02 & 47 & 0.54 & 1.22 & 32.8 & 0.83 & 7.11 & 92 & 14.3 \\
\hline 12 & Children's Hospital of Mexico "Federico Gómez" & 1165 & 50.64 & 5.96 & 35 & 0.36 & 0.85 & 37.17 & 1.03 & 6.27 & 77 & 15.1 \\
\hline 14 & $\begin{array}{l}\text { National Institute of Psychiatry } \\
\text { "Ramón de la Fuente Muñiz" }\end{array}$ & 907 & 71.33 & 34.33 & 59 & 2.07 & 3.24 & 40.35 & 5.29 & 13.56 & 92 & 9.8 \\
\hline 17 & General Hospital of Mexico & 789 & 61.22 & 12.72 & 44 & 0.76 & 1.57 & 37.26 & 3.42 & 10.65 & 45 & 17.5 \\
\hline 20 & National Institute of Genomic Medicine & 527 & 67.17 & 19.94 & 37 & 1.20 & 1.63 & 31.31 & 2.28 & 9.11 & 48 & 10.9 \\
\hline 31 & Central Hospital "Dr. Ignacio Morones Prieto" & 267 & 55.81 & 18.98 & 23 & 1.14 & 2.27 & 23.97 & 3.37 & 8.24 & 0 & NA \\
\hline
\end{tabular}

Source: Created by the authors with WoS and Conacyt Beneficiaries' Registry data. Ndoc = number of documents, $\mathrm{CD} \%=$ cited documents percentage, $\mathrm{Cl}=\mathrm{citation}$ index, $\mathrm{H}=\mathrm{Hirsch}$ index IRW = impact relative to world, $\mathrm{CNCl}=$ category normalized citation impact, IC \% = percentage of documents with international collaboration, EXC $\%=$ production of excellence (percentage of articles within most-cited 1\%), HP \% = high performance production (percentage of articles within most-cited $10 \%$ ), SNI = Members of the National System of Researchers 2017 . $\mathrm{SP}=$ institutional scientific production (Ndoc/SNI).

that it exceeded world average. As for INCan, although from 2010 to 2013 its works had a low impact, in six of the 11 years of the period its impact exceeded the national mean and the international mean in five (Figure 2).

In order to better understand the results obtained for INCan, they were located in the national context of scientometric performance in the biomedical area. Table 2 shows the results obtained for the 10 Mexican health institutions indexed in WoS during the 20072017 period. In this ranking, INCan is located at place five out of 10 .

The data in Table 2 were processed by means of the ViBlioSOM methodology to practice a multidimensional analysis in order to find the different scientometric performance profiles of the institutions and represent them in topographic clusters according to their similarities. Five indicators were chosen to represent each institution: SP, $\mathrm{HP} \%, \mathrm{EXC} \%, \mathrm{CNCl}$ and IC \%. Consequently, for the neural network, each institution is a five-dimensional mathematical object (vector). During the training, the network simultaneously considers the five dimensions to organize the institutions on the map, placing the most similar institutions in a close position.

The artificial neural network automatically generates the maps shown in Figure 3. On map A, INCan is grouped with the National Institute of Medical Sciences and Nutrition "Salvador Zubirán" (INCMNSZ - Instituto Nacional de Ciencias Médicas y Nutrición
"Salvador Zubirán"), which means that during the study period these institutions exhibited a similar scientometric profile. Conversely, the behavior of the other institutions differs enough to be positioned in different clusters. Maps B to F correspond to one of the five indicators. The green color corresponds to the lowest value, the yellow color to the mean and the red color to the highest value (Figure 3).

The orange color for INCan on map B indicates that it is in the group of the second most productive institutions, i.e. those with the largest number of articles per SNI member, after General Hospital of Mexico, Children's Hospital of Mexico "Federico Gómez" and INCMNSZ. As for impact, map E places INCan in the mean, together with the National Cancer Institute and INCMNSZ. The $\mathrm{CNCl}$ indicator indicates that INCan exceeds the global mean in terms of impact. The indicators on maps $C$ and $D$ are quality indicators and, in both, INCan has low values. During the studied period, it produced scarce research of excellence (EXC \%) and high performance research (HP \%). Map $F$ shows that INCan's behavior regarding international collaboration is low, as in the other institutions.

\section{Discussion}

The fact that INCan is located among the most scientifically productive Mexican institutions is an irrefutable positive indicator. The first place in the ranking is for the Mexican Institute of Social Security, an 

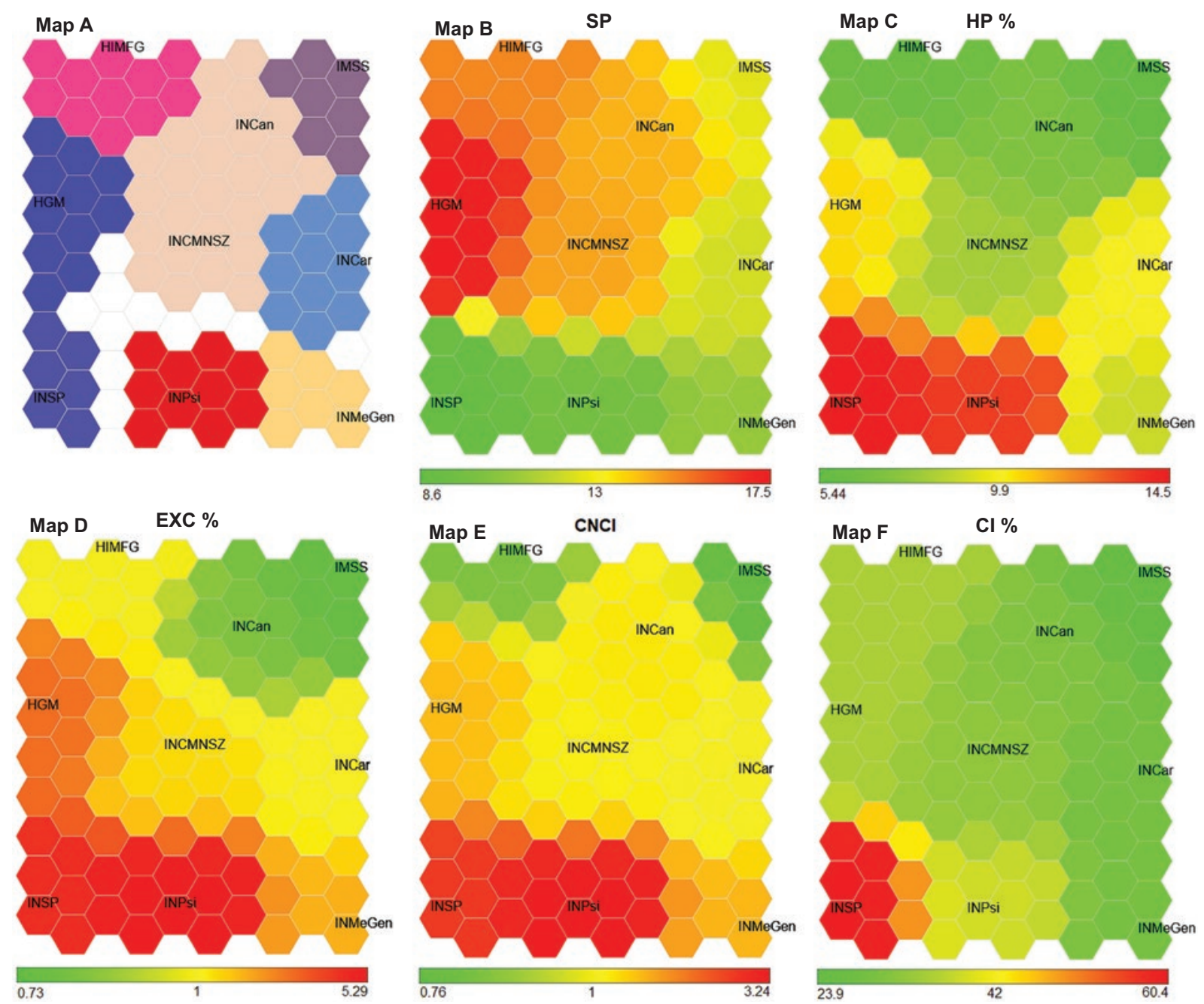

Figure 3. Topographic maps resulting from the multi-parametric analysis with ViBlioSOM. HIMFG: Children's Hospital of Mexico "Federico Gómez", IMSS: Mexican Institute of Social Security, INCan: National Cancer Institute, HGM: General Hospital of Mexico, INCMNSZ: National Institute of Medical Sciences and Nutrition "Salvador Zubirán", INCar: National Institute of Cardiology, INSP: National Institute of Public Health, INPsi: National Institute of Psychiatry, INMeGen: National Institute of Genetic Medicine. Source: Own creation with WoS data using the LabSOM tool.

institution that was assigned $49.1 \%$ of the net budget for the Health Sector. In 2017, the Mexican Institute of Social Security allocated 727.1 million Mexican pesos to research and had 324 researchers who were SNI members; therefore, it is not surprising that it published the largest number of documents. With that being said, the relationship between annual budget and total number of published documents is not linear: the National Institute of Public Health (INSP - Instituto Nacional de Salud Pública), INCMNSZ and the National Institute of Cardiology had assigned a lower budget than INCan and published more.

The number of researchers who are members of the $\mathrm{SNI}$ is more directly correlated with the number of publications than the budget. The ranking of institutions that is generated by the number of SNI members is almost equal to the number of published documents. This correlation has the advantage of being a resource for comparing the institutions taking into account only the resources allocated to research. For example, although total absolute number of documents published by the Mexican Institute of Social Security is much higher than that of INSP, INSP institutional scientific productivity and citation index are higher. In the institutional scientific productivity ranking, INCan is at fourth place.

The maps in Figure 3 reveal the discrepancy between quantitative and qualitative productivity. The areas of the map that correspond to quality (red areas in maps $C, D$ and $E$ ) do not match those of productivity. If the institutions are listed by their citation index, INCan appears in number 8 out of 10 . When 
delving into the analysis of INCan's exclusive production, we find that of the 1,323 documents published in the period, 633 did not have a single citation. That is, 52.15 percent of the published documents generated the 12,243 accumulated citations.

In fact, the 11 highly cited papers $(0.78 \%)$ generated $26.9 \%$ of all citations. The scientometric behavior of the article "Nivolumab versus docetaxel in advanced non-squamous, non-small-cell lung cancer" is even more atypical. Its impact has been such, that the year of its publication is the only one where the average number of citations per INCan article (11.01) almost doubled the world average (5.94), whereas in all other years it was below. This article is an outlet that modifies the dynamics of the system. Without it, INCan would be ranked last in the list by citation index.

Of the 583 institutions INCan collaborated with, 223 appear on the list only once. The most intense collaboration in terms of number of articles and permanence in time, was with the most scientifically productive Mexican institutions, which is also a good indicator of INCan researchers' level. Among the international collaborations with higher durability and productivity, those established with US institutions are predominant.

The multi-parametric analysis indicates that the majority of Mexican public health institutions have achieved high productivity and impact with a low percentage of international collaborations, with the exception of INSP, which has a low productivity (low SP), but high quality (high $\mathrm{CNCl}$ ) profile and the highest values in production of excellence (EXC \%), high performance (HP \%) and international collaboration (IC \%).

The subjects and journals where INCan researchers publish the most and have the highest impact are those that link oncology to clinical research. The link between research and clinical care a national institute enables has been positively exploited by INCan researchers. In contrast, the publications clearly show a deficit in research on medical education, another one of INCan's primary activities, and that should help address the deficit of oncologists Mexico has.

Another neglected research subject is social medicine. Cancer in Mexican disadvantaged population evinces social inequalities and exacerbates them. Therefore, developing research that contributes to design and implement culturally appropriate programs that take into account social determinants and behavioral factors that increase the risk of suffering from cancer is a priority, through interventions that include gender, intercultural and community-based approaches.

\section{Conclusions}

Although peer review is irreplaceable and can conclusively establish the relevance of a scientific research, scientometry specialists have strived to design new standardized and size-independent indicators that allow measuring and fairly comparing the activity of different scientific communities. On the other hand, scientific activity cannot be evaluated considering one or two variables, given that, like any social activity, it is a complex multidimensional phenomenon. Scientometric profiles resulting from the multi-parametric analysis with SOM allow an institutional, comprehensive diagnosis of scientific performance, considering several dimensions simultaneously. Globally, INCan exhibits a scientometric profile with a high mean productivity and normalized impact above the world mean. Its areas of opportunity are found in the production of excellence (EXC \%) and high performance (HP \%) dimensions.

\section{Acknowledgements}

Alí Ruiz Coronel thanks Programa Cátedras CONACyT for the support to project 479.

\section{References}

1. Instituto Nacional de Cancerología. Estatuto orgánico. México: INCan; 2016.

2. Instituto Nacional de Cancerología 2003-2013. México: INCan; 2013.

3. Garfield E. The history and meaning of the journal impact factor. JAMA. 2006;295:90-93.

4. Lewinson G, Purushotham A, Mason M, McVie G, Sullivan R. Understanding the impact of public policy on cancer research: a bibliometric approach. Eur J Cancer. 2010;46:912-919.

5. Lewinson G y Markusova V. The evaluation of Russian cancer research. Research Evaluation. 2010;19:129-144.

6. Sullivan R, Lewinson G, Purushotham AD. An analysis of research activity in major UK cancer centres. Eur J Cancer. 2011;47:536-544.

7. Kaur H, Mahajan P, Gupta BM. Scientometric analysis of the research output: a study of Government Medical College and Hospital (GMCH) Chandigarh. Collnet J Scientometrics Inform Management. 2011; $5: 217-226$.

8. Abeguende DO, Mathers CD, Adam T, Ortegon M, Strong K. Breakaway: the global burden of cancer. Challenges and opportunities. Inglaterra: Economist Intelligence Unit; 2007.

9. Essential Science Indicators. [En línea]. EE. UU.: Clarivate Analytics; 2019.

10. Villaseñor E, Arencibia-Jorge R, Carrillo-Calvet H. Multiparametric characterization of scientometric performance profiles assisted by neural networks: a study of Mexican higher education institutions. Scientometrics. 2016;10:77-104. 